\title{
Transnational Building Practices: Knowledge mobility and the inescapable market
}

Please cite as:

Faulconbridge JR (2015) Transnational building practices: knowledge mobility and the inescapable market. Global Networks 15 (3) 275-287

James Faulconbridge, Lancaster University, UK (j.faulconbridge@lancaster.ac.uk)

Monika Grubbauer, Technische Universität Darmstadt, Germany (grubbauer@stadtforschung.tudarmstadt.de)

\begin{abstract}
Architecture and urban planning have always been subject to, and affected by, processes of transnational cultural exchange and professional networking. Yet, the modes and geographies of knowledge mobility in urban development have matured in the last two decades, with various forces resulting in faster, more frequent and more impactful forms of transnational learning. The papers in this special issue provide an important contribution to understanding this maturation, highlighting the particular ways that knowledge and practice relating to building design move from place to place. In this introductory paper, we develop an analysis of how transnational building practices come to be. We highlight the way that transnational building practices can both deepen our knowledge of the constitution of knowledge mobility, and exemplify the profound tensions that result from the clash between the structuring logic of international markets and the need to adapt global ideas to local contexts. Thus, in addition to de-naturalising mobility and teasing out how movement is manufactured, we draw attention to the way that the inescapable relationships between buildings and markets determine the trajectories and effects of transnational knowledge networks. This opening up of the political economy of mobility, we believe, is one of the most pertinent issues in relation to considerations of mobility more broadly.
\end{abstract}

Keywords: knowledge mobility, building practices, architecture, international markets 


\section{Introduction}

Architecture and urban planning have always been subject to, and affected by, processes of transnational cultural exchange and professional networking (Nasr and Volait 2003; King 2004; Ward 2006, 2010). Studies, such as those of the globalization of American tall building architecture (Cody 2003) and the bungalow (King 1984), show that global networks of knowledge are anything but new. Yet, the modes and geographies of knowledge mobility in urban development have matured in the last two decades, with various forces resulting in faster, more frequent and more impactful forms of transnational learning. This special issue provides an important contribution to understanding this maturation, highlighting the particular ways that knowledge and practice relating to building design move from place to place.

In this introductory paper we take inspiration from the contributions to the special issue and develop an analysis of how transnational building practices come to be. In addition to de-naturalising mobility and teasing out how movement is manufactured, we draw attention to the way that the inescapable relationships between buildings and markets determine the trajectories and effects of transnational knowledge networks. This draws our attention to both the similarities that exist between transnational flows of knowledge relating to buildings and policies, and the unique ways that market imperatives associated with financialized urban development (Halbert et al. 2014; Torrance 2008) exacerbate some of the neoliberal, market-induced dynamics of mobility. As such, we show through our introduction, and the papers in the special issue offer more detail about, the way that transnational building practices can both deepen our knowledge of the constitution of knowledge mobility, and exemplify the profound tensions that result from the clash between the structuring logic of international markets and the need to adapt global ideas to local contexts.

\section{The making of knowledge mobility}

If we have learned one thing from the proliferating body of work on knowledge mobility (Faulconbridge 2013, 2015; McCann 2011; Peck, 2011; Peck and Theodore, 2010; Prince 2012; Ward 2006), it is that the movement of knowledge and ideas from place to place is far from a natural phenomenon. Things are made to move as part of "fundamentally social processes of knowledge circulation" (McCann 2011: 111) and this involves a range of actors and technologies that help constitute relational spaces of flow. As far as buildings and building practices are concerned, we can in the first instance identify a number of developments in the 1990s and early 2000s that help constitute the latest phase of mobility. 
First, processes of economic restructuring and socio-political rescaling have made cities key actors as well as nodes in neoliberal policy regimes (Brenner and Theodore 2002). Learning and comparison through urban policy transfer, policy tourism, and best practices (Tait and Jensen 2007; González 2011; Grubbauer 2013) have thus become central to the production of global knowledge regimes (Healey and Upton 2010). This has inspired, second, the intensification of the globalization of architecture and planning communities and firms (most notably celebrity architects and large architecture and planning firms such as Aedas and Arup). These actors have the resources and incentive to open up spaces of knowledge flow that come to shape urban development (Faulconbridge 2010, 2013; Knox and Taylor 2005; McNeill 2008; Ren 2011). Third, the securitization of real estate assets and the financialization of real estate markets have profoundly altered the spatial networks of power in real estate development since the 1990s (Coakley 1994; Lizieri 2009). Contemporary urban spaces cannot be understood without analysis of the impacts of international property investors who have become important stakeholders in the decision-making processes associated with urban infrastructures such as buildings (Moulaert et al. 2003; Zukin 2009), and who give shape to the knowledge networks that define urban design priorities.

The papers in this special issue develop, in various ways, all of these themes. As the foundations for mobility, such political-economic developments are the starting point for understanding why and how knowledge moves. We return to questions about neoliberal markets again below, but before doing so should pause for a moment to consider how, in the context of such regimes, mobility actually happens.

As Kong (2014: 274) notes, people, technology, finance, and images are fundamental to the mobility of knowledges between cities, these both themselves moving but also opening up spaces of flow. Existing research has shown that such factors are significant in relation to architecture and buildings: for instance, Sklair (2005) demonstrates how a transnational capitalist class construct architectural globalization; Faulconbridge (2010) describes the technologies used in global architecture firms to mobilise knowledge between offices; D'Arcy (2009) notes the emergence of institutional arrangements that allow global real estate investors to operate; and Grubbauer (2010) documents how experiences through images, advertisement and media coverage allow knowledge to move. The papers in this special issue take such analyses one step further and provide rich empirical scrutiny of how factors such as strategic interventions by firms, practices of benchmarking, comparison and referencing, the spread of building technologies and materials, and transnational rules and norms mediate mobility.

Georg (this issue) analyses the use of a sustainability assessment tool and its mediating of interactions between professionals, pointing us towards the crucial role of models as a technology of 
knowledge mobility. Faulconbridge and Yalciner (this issue) similarly highlight the role of models, in their case this being the Building Research Establishment Environmental Assessment Model (BREEAM). They demonstrate how models not only act as a means of mobilising knowledges, but also as a form of control that imposes movement, even if it is not desired. Rapaport (this issue) provides an ethnographic account of the everyday practices and social interactions through which planning ideas travel. She examines how international private sector architecture, engineering and planning consultants mobilize ideas about sustainable urbanism in their efforts to convince clients of their proposals and the ways clients respond to these. It is shown how the consultants, to allow clients to "inhabit" the idea of sustainable urbanism, use visual media and personal experiences such as study tours to create powers of seduction and persuasion which create demand for knowledge mobility.

It is clear, then, from the analysis offered by these papers that the making of knowledge mobility in relation to building practices is deliberate and tied to the interests of the groups involved. De-naturalising mobility and asking how it happens reveals the significant efforts by interested parties in creating technologies and social contexts that enable movement and which serve the capital accumulation priorities of those involved. This, then, returns us to questions of markets.

\section{Buildings, markets and regimes of mobility}

The relationship between buildings and markets has been documented extensively. The post-World War II era heralded the birth of property markets as we now recognise them but the history of such markets extends back to at least the early $20^{\text {th }}$ century (Scott, 2013; Willis 1995). There is much that could be said about property markets, but we restrict ourselves here to questions about their influence on transnational knowledge mobility. At the heart of this issue are the investors in commercial real estate, in the form of both property developers and the banks that finance such operations. As Torrance (2008) argues, networked financial products that fund investment in property and enable the work of global investors define in important ways the agendas that transnational knowledge mobilities must service in the urban context. Indeed, "All forms of policy transfer and learning are embedded in discursive paradigms, ideational circuits, institutional frameworks, and power structures" (Peck 2011: 785), in the case of buildings this relating to the standards, financial structures, and assessments of performance that are imposed on a building by investors regardless of its location.

Particularly important are the institutions of global property markets that both enable the worldwide activities of property investors and developers, and which shape/enact knowledge mobility through their networks, technologies and calculative practices. D'Arcy (2009) describes how 
the globalization of property investment has required new institutions, i.e. rules, norms and cultural standards, which ensure that investors can overcome information deficits in a new market. This, like in other cases of transnational governance (Djelic and Quack, 2003), takes the form of 'best practices' and standards that are imposed on those building 'investment grade' property around the world. The implications for knowledge mobility relate to the way this compels those designing and constructing buildings to learn about and reproduce 'models' associated with transnational institutions, these often originating from North America and Western Europe. As such, property markets have generated crucial technologies of mobility, and associated power relations, which enforce mobility through the adoption of norms and standards.

The papers gathered here illustrate the effects of property markets on knowledge mobility in a variety of ways. Heeg and Bitterer (this issue) examine the introduction of international design and building norms as part of the internationalization of Warsaw's office property market. The focus is on the interplay between global and local property professionals and the resulting new institutional arrangements. The authors argue that international property consultants, through their networks, shared training programs and regular communication, are part of global communities of practice. They act as "market-making intermediaries", establishing shared understandings of requirements in real estate practice that guide the establishment and acceptance of international norms and standards in local markets. Faulconbridge and Yalciner (this issue) outline how BREEAM has become a vector for knowledge mobility because of the way it allows international comparisons and the benchmarking of buildings, this meaning that knowledge of how to design and build in ways that enhance the BREEAM rating of a building are crucial for those operating in the commercial property world. Grubbauer (this issue) highlights the intimate relations between architectural and planning practices and the construction industry, and in turn how links to international commercial property developers shape building practices in local markets. She draws on the example of shopping centre developments in Central and Eastern Europe (CEE) over the past two decades. Analysing the case of the German ECE group and its expansion into the CEE region she argues that construction has a key role in realizing buildings as commercial products built to international standards.

Buildings provide, then, an important way of further exploring the way markets structure the movement of knowledge. The papers in the special issue together reveal the imperatives of standardisation, comparability, and best practice that both motivate knowledge mobility but also condition the types of knowledge that move. This reminds us of the interests served by mobility, and the importance of politicising mobility as a manifestation of power relations within the global economy. It certainly questions approaches that see knowledge mobility as a solution to knowledge deficits, highlighting mobility as a 'solution' to a 'problem' created by those set to gain from the 
movement of knowledge into new places. Indeed, in the case of buildings, this leads to important questions about the implications of knowledge mobilities for situated and vernacular design.

\section{Importation, adaptation and the situating of mobile knowledges}

Perhaps one of the greatest controversies in the literature on globalization and buildings relates to the impacts of mobile knowledge on the maintenance of situated local (vernacular) design (see, for instance, Cole and Lorch 2003; Faulconbridge 2009; Grubbauer 2014; Moore 2013). Whilst a far from settled debate, one of the most important insights to date has been that local design practices are remarkably robust, and even apparently 'global' designs such as the bungalow or skyscraper have important local material and cultural manifestations (Bunnell 1999; Jacobs 2006; King 1984). This tallies with insights from the policy mobilities literature that notes a tendency for movement to involve transformation (McCann 2011; Peck and Theodore 2010), this perspective being an important differentiator of this work from studies of diffusion.

Theoretically, we might think about the apparently fluid nature of knowledge and its continual reproduction during mobility in two ways. Literatures that take theorisations of knowledge as their starting point draw attention to the inherently processual, cognitive, and practice based nature of the learning processes that allow knowledges to move (Amin and Cohendet 2004; Faulconbridge 2006; Vallance 2011). From such a perspective, mobility appears as a process of constant learning in which different individuals and groups come to develop their own understandings of design models and practices. This prevents forms of strong convergence because of the constant translation and reproduction of knowledges. Literatures that adopt an institutional perspective offer a different and more structural interpretation. They focus upon the way the institutional environment of the places mobile knowledges arrive at determine both whether adoption occurs and the types of adaptation this might involve. Studies have shown that combinations of the socio-cultural legitimacy of particular practices (Boxenbaum and Battilana 2005), and the way institutions determine the availability of the skills and supporting infrastructure needed for adoption (Eick 2012), as well as conflicts or synergies with already existing knowledges, practices, and regulations (Peck and Theodore 2010), all influence the impacts of knowledge mobilities.

The papers in this special issue develop such themes by revealing the complex dialectic between the efforts of interested parties to make certain knowledges move, market imperatives, and processes of learning and institutional embedding. In particular, they provide an important set of insights into the different kinds of influence that matter in the case of buildings, but which are also likely to have wider relevance to other types of knowledge mobility. This influence relates, in 
particular, to the constant tussle between the efforts of those seeking to mobilise and stabilise knowledges, and the learning and institutional processes that inhibit frictionless movement.

Georg (this issue) argues that because there are multiple uses of 'sustainability' in framing urban development plans, there are multiple ways in which globally circulating models of sustainability translate into local design 'solutions'. She shows how artefacts such as tools, reports, and visualizations coordinate, challenge and change existing practices through a learning process. The analysis thus highlights the complexity, and temporal stability and instability, that underlies the materialization of ideas about the sustainable city and the ways in which the assessment tool mediates and restricts choices of design. A similar story emerges from the article by Faulconbridge and Yalciner (this issue). Their analysis points to the way the mobility of BREEAM was inherently challenged by the local specificities of sustainable building design, but also how those mobilizing the model sought to prevent these challenges from compromising global standards. When read in parallel to Georg's analysis, the story of BREEAM shows that the effect of learning and institutional processes is to create frictions that if not preventing certainly render hard work the reproduction of knowledges in new places. Indeed, perhaps the most important insight of the two analyses is that with significant work models can be made to move in a relatively stable way, but even in the context of such work this stability is constantly under threat and in need of reproduction. Rapoport (this issue) also demonstrates the inherent instability of knowledges on the move. In her analysis, travelling models of sustainable urbanism re-emerge out of the repeated take-up of ideas in new contexts, but this re-emergence remains unpredictable. This in some ways mirrors the findings of Grubbauer (this issue) who reveals that whether and how design and planning ideas travel depends on the particular construction practices and technologies available in a local market. Unavailability threatens to prevent effective movement, but as Grubbauer shows, by making products, materials and technologies available, as part of marketization efforts in the construction sector, the circulation of design and planning solutions is made possible despite apparent adversities.

Perhaps what is most important about the papers in the special issue is how they draw attention to the inherent tendency for knowledges to mutate as they travel, but also to the strenuous efforts made by different parties to minimise this when it threatens their interests. Whether it be those selling a model, or those buying and using a model to enable their transnational capitalist activities, agents of mobilization put significant efforts into ensuring that adaptation and situating do not undermine the benefits accrued from importation. This further highlights the politics of mobility, and in the case of buildings reminds us that whilst the inherent robustness of vernacular design practices thanks to local building regulations, cultures, and materialities should not be underestimated, nor should the power and efforts of those seeking to mobilise knowledges. The 
struggle that emerges means that, in a dynamic case-by-case way, we see building infrastructures being transformed to a greater or lesser extent by knowledge on the move.

\section{Conclusions: agents, trajectories and political economy}

Although the remit of this special issue is to consider the specifics of transnational building practices and the knowledge mobilities that underlie them, the implications of the insights developed by the papers stretch beyond the world of buildings. We would not want to underestimate the importance of the analyses for better understanding transnational building practices: they clearly reveal the significance of the very material form of the building, say compared to a public policy, and in turn a particular role for strategies that make mobility through technical models, images, and as well as people on the move. But, the opening up of the politics of mobility, and in particular the influence of markets on mobility, is important to considerations of mobility more broadly.

What clearly emerges from the special issue is a story of agents and trajectories of knowledge mobility intimately related to the laws of the markets. This is perhaps more apparent in the case of buildings than in other forms of knowledge mobility given the intensely financialized nature of property. This implies that buildings provide a useful lens through which to view the relations between mobilities and neoliberal economic environments that others have established as being important. In particular, it reminds us that transnational practices and knowledge mobilities cannot be understood without careful consideration of the wider political economy in which they operate. The papers reveal that the political economy matters because of how it can encourage and enable mobility, the market imperatives for mobilisation and standardisation being very clear, and also because it can affect the extent to which the inherent tendency for mutation during mobility leads to locally situated reproductions of mobile knowledges. Most fundamentally, this relates to questions about the power of markets, the work that makes markets function, and the way this work ensures mobility and at times close down possibilities for local adaptions.

This special issue has, then, begun to further open up the connections between mobility and markets. Future work might develop this both in relation to buildings and knowledge mobilities more broadly. We see two useful directions for such a future agenda.

First, there are questions about the relationships between the trajectories of knowledge mobility and power structures in the world economy. One of the benefits of recent debates about knowledge mobility has been to point out the "embodied, material, piece-meal and often irrational" nature (Jacobs 2012: 414) of travelling knowledges. This finding can be usefully (re)connected with 
the insights of economic geographers into the organizational logics of international markets. Scholars who have sought to integrate research on global cities and that on the governance of commodity chains have pointed towards the role and spatial concentration of higher-valued producer service firms involved in organizing and structuring their clients' cross-border business networks (Brown et al. 2010; Parnreiter 2015). In addition, there is evidence of the unprecedented dominance of a limited number of transnational corporations in the global economy, coupled with the emergence of a global corporate elite (Carroll 2009). Clearly, then, some firms are more powerful than others, some cities have a higher concentration of business decision-making capacities, and some knowledges will affect markets more than others. A crucial question is, therefore, whether and at what point knowledges need to be stabilized to allow for their effective mobilisation and what kind of power relations allow for this stabilization and mobilization to occur. Following from this, we might ask where those doing the stabilization work are based and hence how the geographies of mobile knowledges intersect with the geographies of control that structure operations within international markets. Which capitalist actors are choreographing knowledge mobility, using what forms of power, to serve what interests, and with what implications? This has broad relevance to all questions of knowledge mobility, but is especially relevant to buildings and real estate because of the complexities of the building as commercial product resulting from the spatial fixity of property and the high financial risks involved in its production. This results in the concentration of power and influence in the hands of a few and thus makes the questions above especially pertinent. This kind of agenda means understanding the manufacturing of movement of knowledge as infused with power and as primarily tailored to certain ends, most notably to enhance the capacity to sell products and accumulate capital. The significance of this is captured by recent suggestions, for instance in global city research, that studies need to go beyond quantifying approaches and substantiate claims about the management and control functions exercised in global cities (Parnreiter 2014; Watson and Beaverstock 2014).

The second agenda for future research takes issue with relationships between knowledge mobility and emerging forms of transnational governance. Again, the question is broadly about at what point and through what means knowledges are stabilized, in this case through and to inform transnational rule-making. Scholars have stressed the plurality of standards and norms that regulate economic activity (Djelic and den Hond 2014), with legally binding norms being supplemented by a range of non-binding 'soft' rules. Rule making is not confined to the nation-state any more but produced by a "multiplicity of regulatory actors fighting for attention, resources and authority in multicentered and fluid arenas" (Djelic and Sahlin-Andersson 2006: 5). How is the manufacturing of mobile knowledge linked to these struggles for regulatory power? How does the plurality of standards and norms operate in the various instances in which knowledge are made to move and/or 
stabilized? One major driver of such new forms of rule-making is marketization, coupled with the rescaling of professional regulation which affects professionals and their activities (Faulconbridge and Muzio 2012). The case of certified sustainable products in the agro-food sector examined by Ponte and Chains (2013), for instance, shows how these new products are introduced by "multistakeholder initiatives that establish and manage base codes, standards, certifications and labels", thus "partly reshap[ing] the structure and characteristics of commodity flows" (ibid.: 459). The ability of developing countries and particularly small-scale actors to intervene in these processes depends, as Ponte and Chains show, not only on overcoming structural disadvantages but also on the mobilization of expert knowledges to their advantage. The crucial connection between the manufacturing of knowledge mobility, norm-making and marketization lies, then, in the interests that are served: transparency in the case of property markets, for instance, does usually serve the interests of those who are in the position to define the criteria. As Sassen (2006: 247) notes: "We can see a new normativity derived from the operational logic of the capital market [...] This brings with it strengthened possibilities of norm-making in the interests of the few rather than the majority. In itself this is not novel. What is novel is the formalization of these privatized norm-making capacities and the sharper restricting of who might benefit [...]". With international institutions such as the World Bank and the IMF becoming increasingly involved in urban policy making within the frameworks of the "urban age discourse" (Gleeson 2013; Brenner and Schmid 2014), and with the contemporary development processes in cities becoming increasingly dependent on contractual negotiations and risk-assessment procedures (Raco 2014; Halbert and Rouanet 2013) and on smart information technologies that are used to regulate and manage urban systems (Klauser et al. 2014), investigating the links between knowledge mobility and transnational regulatory regimes seem crucial. The conceptual and empirical challenge is, therefore, to scrutinize the role of the travelling, circulation, regularization and adaption of mobile urban policies and circulating ideas in the making of new supra-regional and transnational forms of urban governance. This, like the first future agenda and like this special issue, is an issue of relevance to and can be studied through buildings and real estate, but is of wider importance to debates about knowledge mobility. This special issue opens-up, therefore, what are arguably some of the most pertinent issues in relation to knowledge mobility as the political economy of mobility and its effects grows in significance as an area of study.

\section{References}

Amin, A. and P. Cohendet (2004) Architectures of knowledge: Firms capabilities and communities, Oxford, Oxford University Press. 
Boxenbaum, E. and J. Battilana (2005) 'Importation as innovation: Transposing managerial practices across fields', Strategic Organization, 3, 355-83.

Brenner, N. and C. Schmid (2014) 'The "Urban Age" in question', International Journal of Urban and Regional Research, 38 (3), 731-755.

Brenner, N. and N. Theodore (2002) 'Cities and the geographies of "actually existing neoliberalism"', Antipode, 34, 349-78.

Brown, E. D., C. Parnreiter, W. Pelupessy, P.J. Taylor and F. Witlox (2010) 'World City Networks and Global Commodity Chains: towards a world-systems' integration', Global Networks 10 (1), 12-34.

Bunnell, T. (1999) 'Views from above and below: The Petronas Twin Towers and/in contesting visions of development in contemporary Malaysia', Singapore Journal of Tropical Geography, 20, 1-23.

Carroll, W. K. (2009) 'Transnationalists and national networkers in the global corporate elite', Global Networks, 9 (3), 289-314.

Coakley, J. (1994) 'The integration of property and financial markets', Environment and Planning A, $26(5), 697-713$.

Cody, J. W. (2003) Exporting American architecture, 1870-2000, London \& New York, Routledge.

Cole, R. J. and R. Lorch (eds) (2003) Buildings, culture and environment. Informing local and global practices, Oxford, Blackwell.

D'Arcy, E. (2009) 'The evolution of institutional arrangements to support the internationalization of real estate involvements. Some evidence from Europe', Journal of European Real Estate Research, 2 (3), 280-293.

Djelic, M. L. and S. Quack (2003) 'Theoretical building blocks for a research agenda linking globalization and institutions', in M.L. Djelic and S. Quack (eds) Globalization and institutions: Redefining the rules of the economic game, Cheltenham, Edward Elgar.

Djelic, M.-L. and K. Sahlin-Andersson (eds) (2006) Transnational governance: institutional dynamics of regulation, Cambridge: Cambridge University Press.

Djelic, M.-L. and F. den Hond (2014) 'Introduction: multiplicity and plurality in the world of standards', Business and Politics, 16 (1), 67-77.

Eick, V. (2012) 'The co-production of purified space: hybrid policing in German Business Improvement Districts', European Urban and Regional Studies, 19, 121-36.

Faulconbridge, J. and D. Muzio (2012) 'The rescaling of the professions: towards a transnational sociology of the professions', International Sociology, 27, 109-25. 
Faulconbridge, J. R. (2006) 'Stretching tacit knowledge beyond a local fix? Global spaces of learning in advertising professional service firms', Journal of Economic Geography, 6, 517-40.

Faulconbridge, J. R. (2009) 'The regulation of design in architecture firms: embedding and emplacing buildings', Urban Studies, 46, 2537-54.

Faulconbridge, J. R. (2010) ‘Global architects: learning and innovation through communities and constellations of practice', Environment and Planning A, 42, 2842-58.

Faulconbridge, J. R. (2013) 'Mobile 'green'design knowledge: institutions, bricolage and the relational production of embedded sustainable building designs', Transactions of the Institute of British Geographers, 38, 339-53.

Faulconbridge, J. R. (2015) 'Mobilising sustainable building assessment models: agents, strategies and local effects', Area, 47, 116-23.

Faulconbridge, J.R. and S. Yalciner (this issue) 'Local variants of mobile sustainable building assessment models: the marketization and constrained mutation of BREEAM ES', Global Networks

Georg, S. (this issue) 'Building sustainable cities: tools for developing new building practices?', Global Networks

Gleeson, B. (2013) 'What role for social science in the 'Urban Age'?', International Journal of Urban and Regional Research, 37 (5), 1839-1851.

González, S. (2011) 'Bilbao and Barcelona "in motion": how urban regeneration "models" travel and mutate in the global flows of policy tourism', Urban Studies 48 (7), 1397-1418.

Grubbauer, M. (2010) 'The high-rise office tower as a global type: exploring the architectural world of Getty Images', in M. Guggenheim and O. Soderström (eds) Re-shaping cities: how global mobility transforms architecture and urban form, London: Routledge, 63-80.

Grubbauer, M. (2013) 'Mainstreaming urban interventionist practices: the case of the BMW Guggenheim Lab in Berlin', Footprint, 13, 123-130.

Grubbauer, M. (2014) 'Architecture, economic imaginaries and urban politics: the office tower as socially classifying device', International Journal of Urban and Regional Research, 38 (1), 336359.

Grubbauer, M. (this issue) 'Circulating knowledge, marketization and normmaking: international developers and construction firms in Eastern Europe since 2000', Global Networks

Halbert, L., J. Henneberry and F. Mouzakis (2014) 'The financialization of business property and what it means for cities and regions', Regional Studies, 48 (3), 547-550. 
Halbert, L. and H. Rouanet (2013) 'Filtering risk away: Global finance capital, transcalar territorial networks and the (un)making of city-regions: an analysis of business property development in Bangalore, India', Regional Studies, 48 (3), 471-484.

Healey, P. and R. Upton (eds) (2010) Crossing borders: international exchange and planning practices, London: Routledge.

Heeg, S. and N. Bitterer (this issue) 'Communities of practice and transnational standards: changing building practices in Warsaw's commercial real estate sector', Global Networks

Jacobs, J. M. (2006) 'A geography of big things', Cultural Geographies, 13, 1-27.

Jacobs, J. M. (2012) 'Urban geographies I: Still thinking cities relationally', Progress in Human Geography, 36 (3), 412-422.

Klauser, F., T. Paasche, and O. Söderström (2014) 'Michel Foucault and the smart city: power dynamics inherent in contemporary governing through code', Environment and Planning D: Society and Space, 32 (5), 869-885.

Kong, L. (2014) 'Transnational mobilities and the making of creative cities', Theory, Culture \& Society, $31(7-8), 273-289$.

Lizieri, C. (2009) Towers of capital: office markets \& international financial services, London: WileyBlackwell.

King, A. (1984) The bungalow: the production of a global culture, London: Routledge/Thoemms Press.

King, A. D. (2004) Spaces of global cultures: architecture, urbanism, identity, London: Routledge.

Knox, P. L. and P.J. Taylor (2005) 'Towards a geography of the globalization of architecture office networks', Journal of Architectural Education, 58, 23-32.

McCann, E. J. (2011) 'Urban policy mobilities and global circuits of knowledge: Toward a research agenda', Annals of the Association of American Geographers, 101, 107-30.

McNeill, D. (2008) The global architect: firms, fame and urban form, London \& New York, Routledge.

Moore, S. (2013) 'What's wrong with best practice? Questioning the typification of New Urbanism', Urban Studies, 50 (11), 2371-2387.

Moulaert, F., A. Rodríguez and E. Swyngedouw (eds) (2003) The globalized city: economic restructuring and social polarization in European cities, Oxford: Oxford University Press.

Nasr, J. and M. Volait (2003) Urbanism - imported or exported?: native aspirations and foreign plans, Chichester: Wiley. 
Parnreiter, C. (2014) Network or hierarchical relations? A plea for redirecting attention to the control functions of global cities, Tijdschrift Voor Economische En Sociale Geografie, 105 (4), 398-411.

Parnreiter, C. (2015) 'Managing and governing commodity chains: the role of producer service firms in the secondary global city of Hamburg', Die Erde, 146 (1), 1-15.

Peck, J. (2011) 'Geographies of policy From transfer-diffusion to mobility-mutation', Progress in Human Geography, 35, 773-97.

Peck, J. and N. Theodore (2010) 'Recombinant workfare, across the Americas: Transnationalizing "fast" social policy', Geoforum, 41, 195-208.

Ponte, S. and E. Cheyns (2013) 'Voluntary standards, expert knowledge and the governance of sustainability networks', Global Networks, 13 (4), 459-477.

Prince, R. (2012) 'Policy transfer, consultants and the geographies of governance', Progress in Human Geography, 36, 188-203.

Raco, M. (2014) 'Delivering flagship projects in an era of regulatory capitalism: state-led privatization and the London Olympics 2012', International Journal of Urban and Regional Research, 38 (1), 176-197.

Rapoport, E. (this issue) 'Sustainable urbanism in the age of Photoshop: images, experiences and the role of learning through inhabiting in the international travels of a planning model', Global Networks

Sassen, S. (2006) Territory, authority, rights: from medieval to global assemblages, Princeton, Princeton University Press.

Scott, P. (2013) The property masters: a history of the British commercial property sector, Abingdon \& New York, Taylor \& Francis.

Sklair, L. (2005) 'The transnational capitalist class and contemporary architecture in globalizing cities', International Journal of Urban and Regional Research, 29, 485-500.

Tait, M. and O. B. Jensen (2007) 'Travelling ideas, power and place: the cases of urban villages and Business Improvement Districts', International Planning Studies, 12 (2), 107-27.

Torrance, M. I. (2008) 'Forging glocal governance? Urban infrastructures as networked financial products', International Journal of Urban and Regional Research, 32, 1-21.

Vallance, P. (2011) 'Relational and dialectical spaces of knowing: knowledge, practice, and work in economic geography', Environment and Planning A, 43, 1098-117. 
Ward, K. (2006) "'Policies in motion", urban management and state restructuring: the trans-local expansion of business improvement districts', International Journal of Urban and Regional Research, 30, 54-75.

Ward, K. (2010) 'Entrepreneurial urbanism and Business Improvement Districts in the state of Wisconsin: a cosmopolitan critique', Annals of the Association of American Geographers, 100, 1177-96.

Watson, A. and J. V. Beaverstock (2014) 'World City Network research at a theoretical impasse: on the need to re-establish qualitative approaches to understanding agency in World City Networks', Tijdschrift Voor Economische En Sociale Geografie, 105 (4), 412-426.

Willis, C. (1995) Form follows finance: skyscrapers and skylines in New York and Chicago, Princeton, Princeton Architectural Press.

Zukin, S. (2009) Naked city: The death and life of authentic urban places, Oxford: Oxford University Press. 